\title{
Effect of Microtopography, Slope Length and Gradient, and Vegetative Cover on Overland Flow through Simulation
}

\author{
Q. Q. Liu ${ }^{1}$ and V. P. Singh, F.ASCE ${ }^{2}$
}

\begin{abstract}
Overland flow on a hillslope is significantly influenced by its microtopography, slope length and gradient, and vegetative cover. A 1D kinematic wave model in conjunction with a revised form of the Green-Ampt infiltration equation was employed to evaluate the effect of these surface conditions. The effect of these conditions was treated through the resistance parameter in the kinematic wave model. The resistance in this paper was considered to be made up of grain resistance, form resistance, and wave resistance. It was found that irregular slopes with microtopography eroded more easily than did regular slopes. The effect of the slope gradient on flow velocity and flow shear stress could be negative or positive. With increasing slope gradient, the flow velocity and shear stress first increased to a peak value, then decreased again, suggesting that there exists a critical slope gradient for flow velocity and shear stress. The vegetative cover was found to protect soil from erosion primarily by enhancing erosion-resisting capacity rather than by decreasing the eroding capability of overland flow.
\end{abstract}

DOI: $10.1061 /(\mathrm{ASCE}) 1084-0699(2004) 9: 5(375)$

CE Database subject headings: Slopes; Infiltration; Kinematic wave theory; Topography; Overland flow; Vegetation; Simulation.

\section{Introduction}

Erosion causes loss of productive soil, diminution of arable land, and harm to the environment. The soil eroded by overland flow eventually finds its way into waterways, and its deposition aggravates riverine flooding. Soil erosion has therefore long been a subject of much interest. The erosion caused by rainfall and consequent runoff is complicated by the interactions of rainfall intensity, soil properties, watershed charactersics, and land use changes. However, in the erosion process the flow of water is of major consequence and so it is fundamental to understand runoff generation and its characteristics.

The past 30 years have witnessed multitudes of investigations on runoff generation, including field observations, experimental studies, theoretical analyses, and mathematical models (Woolhiser and Ligget 1967; Kirkby 1978; Dunne and Dietrich 1980; Parsons and Abrahams 1992; Singh 1996; Putty and Prasad 2000; Wang et al. 2002; Angermann et al. 2002; Singh and Woolhiser 2002). Many aspects of runoff on uniform hillslopes, such as the basic characteristics, the process of runoff generation, the resistance law, the model, and the simulation method, have been investigated extensively (Lima 1989; Wu and Zhou 1994; Yao 1996; Lawrence 2000; Chen and Liu 2001; Chen et al. 2001; Saghafian

\footnotetext{
${ }^{1}$ Institute of Mechanics, Chinese Academy of Sciences, Beijing 100080, China; also, Visiting Professor, Dept. of Civil and Environmental Engineering, Louisiana State Univ., Baton Rouge, LA 70803. E-mail: qqliu@imech.ac.cn or qliu1@1su.edu

${ }^{2}$ Dept. of Civil and Environmental Engineering, Louisiana State Univ., Baton Rouge, LA 70803-6405. E-mail: cesing@1su.edu

Note. Discussion open until February 1, 2005. Separate discussions must be submitted for individual papers. To extend the closing date by one month, a written request must be filed with the ASCE Managing Editor. The manuscript for this paper was submitted for review and possible publication on April 22, 2003; approved on January 16, 2004. This paper is part of the Journal of Hydrologic Engineering, Vol. 9, No. 5, September, 2004. @ASCE, ISSN 1084-0699/2004/5-375-382/\$18.00.
}

et al. 2002; Li et al. 2003). As a result, overland flow over uniform hillslopes is understood reasonably well.

In reality, hillslopes exhibit local irregularities, especially microtopography, and have a vegetative cover. These complex surface conditions exercise significant influence on overland flow and soil erosion. Investigations that discuss runoff generation on the hillslopes with complex surface conditions have been relatively few, a fact that reflects a limited understanding of overland flow over irregular slopes. In recent years, a greater number of people have started paying more attention to runoff generation on irregular surface hillslopes. Abrahams et al. (1992) investigated the resistance of overland flow on gravel-covered semiarid hillslopes and suggested that the total resistance may be divided into grain resistance, form resistance, wave resistance, and rain resistance. Casanave and Valentin (1992) analyzed the effect of surface features on runoff. Posthumus and Spaan (2001) analyzed the rainfall runoff relations for different vegetative covers. Some researchers (Govindaraju et al. 1992; Scoging 1992; Tayfur et al. 1993; Tayfur and Kavvas 1998; Tayfur 2001) numerically studied runoff generation on the complex surface hillslopes by $2 \mathrm{D}$ models. These studies reflected a limited understanding of overland flow over irregular slopes.

Owing to the complexity of surface conditions affecting overland flow, further analyses are essential for understanding overland flow on irregular surface hillslopes. The objective of this study is to investigate the influence of microtopography and vegetative cover on overland flow on hillslopes. To that end, a 1D kinematic wave model in conjunction with a modified version of the Green-Ampt infiltration equation was employed. The results of this investigation will be useful in designing vegetativeprotection measures for mitigating soil loss and soil conservation.

\section{Flow Resistance on Irregular Surface Slope}

Resistance affects the flow velocity, runoff discharge, and shear stress of overland flow. Because the various factors that affect 
resistance and their interactions are complex, it is difficult to quantify the resistance due to each factor. Therefore, borrowing from open-channel flow, the Darcy-Weisbach equation is often used to determine the overall resistance to overland flow. For uniform flow conditions, the Darcy-Weisbach roughness factor, $f$, is expressed as (Chow 1959)

$$
f=\frac{8 g R S_{f}}{u^{2}}
$$

where $g=$ acceleration due to gravity $\left(\mathrm{m} / \mathrm{s}^{2}\right) ; S_{f}=$ friction slope of flow; $u=$ mean flow velocity $(\mathrm{m} / \mathrm{s})$; and $R=$ hydraulic radius that can be approximated by the flow depth $h$ for overland flow (m).

For shallow flow over uniform beds, the resistance to overland flow is mainly related to soil particles, flow Reynolds number R, and rainfall intensity (Wu and Zhou 1994; Yao 1996; Lawrence 2000). The friction factor $f$ is generally considered as inversely proportional to the Reynolds number. However, the conventional relation between $f$ and $\mathrm{R}$ for shallow flow over plane beds applies only where $f$ is entirely due to the grain resistance, which is manifestly not the case on hillslopes with irregular surface forms and vegetative cover. That is, surface conditions markedly affect overland flow, and their influence can be reflected through a resistance law. Hence, analysis of surface runoff on irregular slopes requires determination of roughness coefficients.

Investigations by Abrahams et al. (1992) suggest that the total resistance to overland flow, $f$, may be divided into four parts that depend on their contributory factors: (1) grain resistance $\left(f_{g}\right) ;(2)$ form resistance $\left(f_{f}\right)$; (3) wave resistance $\left(f_{w}\right)$; and (4) rain resistance $\left(f_{r}\right)$. The grain resistance is imparted by soil particles and microaggregates that protrude into the region of flow up to about less than 10 times the thickness, $\delta$, of the viscous sublayer. This resistance is actually the viscous resistance that dissipates kinetic energy as the flow overcomes the no-slip condition at the boundary. The form resistance is exerted by microtopographic protruberances that protrude more than $10 \delta$ into the flow region or give rise to spatially varying flow cross-sections or changing flow directions. The wave resistance is generated when vegetation protrudes above the flow surface and disturbs the free water surface, or more obvious topographic protruberances deform the water surface, or the energy is dissipated in maintaining an uneven water surface. It generally occurs at the base of local depressions in the ground surface and where flow emerges from between large roughness elements. Finally, the rain resistance is due to the velocity retardation as the flow momentum is transferred from accelerating raindrops to the flow velocity. Thus, the total flow resistance can be expressed as

$$
f=F\left(f_{g}, f_{f}, f_{w}, f_{r}\right)
$$

Studies have shown that the rain resistance contributes less than $20 \%$ of the total resistance $f$, but is generally a much smaller proportion for transitional and turbulent flows (Shen and Li 1973; Dunne and Dietrich 1980). Hence, the rain resistance can be neglected without undue loss of accuracy or physical realism. Assuming that the grain resistance and form resistance are additive (Einstein and Banks 1950), Eq. (2) can be rewritten as

$$
f=F\left[\left(f_{g}+f_{f}\right), f_{w}\right]
$$

Abrahams et al. (1992) studied the resistance of overland flow on gravel-covered semiarid hillslopes at the Walnut Gulch Experimental Watershed, Tombstone, Arizona. Combining indoor experiments and Hirsch's (1992) results, Abrahams et al. (1992) developed a resistance formula that included grain, form, and wave components as

$$
\log f=\log \left[3.19 \mathrm{R}^{-0.45}+\frac{4.8 \Sigma A_{i}}{A_{b}}\right]+2.80 C
$$

where $\mathrm{R}=$ Reynolds number of overland flow; $A_{b}=$ area of the bed $\left(\mathrm{m}^{2}\right) ; A_{i}=$ wetted cross-sectional area of the $i$ th element $\left(\mathrm{m}^{2}\right)$; and $C=$ concentration of roughness elements $(\%)$. The first term on the right-hand side of Eq. (4) represents grain resistance, which is similar to the Blasius solution for flow on a semi-infinite plane. The second term indicates the form resistance that can be derived from the resistance formula for cylindrical flow. The third term is the wave resistance.

Rewriting Eq. (4) as

$$
f=e^{2.80 C}\left(3.19 \mathrm{R}^{-0.45}+\frac{4.8 \sum A_{i}}{A_{b}}\right)=k\left(3.19 \mathrm{R}^{-0.45}+b\right)
$$

where $k=e^{2.80 C}$ represents the wave resistance $(k=1-16.445)$ that reflects the influence of the vegetative cover, and $b$ $=4.8 \sum A_{i} / A_{b}$ represents the form resistance which reflects the influence of microtopography. Although in these laboratory studies surface form was represented by employing cylinders, cubes, and hemispheres (Hirsch 1992), it seems likely that the findings would generically relate to overland flow over irregular semiarid hillslopes.

\section{Runoff Generation on Hillslopes}

\section{Overland Flow Model}

On semiarid hillslopes, virtually all surface runoff occurs in the form of overland flow. When the rainfall intensity exceeds the soil infiltration rate, the water begins to accumulate on the slope surface. When the capacity of ponding on slope is exceeded, the water begins to flow down and forms sheet flow under the action of gravity. A 1D kinematic wave model is an accepted model for overland flow (Singh 1996). Shen (1996) reported that runoff generation on the Loess Plateau in China can also be modeled using the kinematic wave approximation (KWA). The governing equations for KWA can be expressed as

$$
\begin{gathered}
\frac{\partial h}{\partial t}+\frac{\partial q}{\partial x}=q^{*} \\
S_{f}=S_{0}
\end{gathered}
$$

where $x=$ coordinate along the flow direction $(\mathrm{m}) ; t=$ time $(\mathrm{s})$; $h=$ water depth $(\mathrm{m}) ; q=$ unit discharge $\left(\mathrm{m}^{2} / \mathrm{s}\right) ; S_{0}=$ slope gradient $\left(S_{0}=\sin \theta\right) ; \theta=$ inclination angle of slope (in degree); and $q_{*}=$ rainfall excess. Chen and Liu (2001) found that the slope surface gradient on the Loess Plateau was significant. Therefore,

$$
q_{*}=p \cos \theta-i
$$

where $p=$ rainfall intensity $(\mathrm{m} / \mathrm{s})$, and $i=$ infiltration rate $(\mathrm{m} / \mathrm{s})$.

Replacing the hydraulic radius $R$ by the flow depth $h$ for overland flow, the kinematic wave velocity can be calculated through Eq. (1) as

$$
u=\sqrt{\frac{8 g h S_{f}}{f}}=\sqrt{\frac{8 g h S_{0}}{f}}
$$

where $f=$ Darcy-Weisbach roughness coefficient; $h=$ depth of overland flow; and $S_{0}=$ slope gradient. Taking Reynolds number $\mathrm{R}=4 u h / v=4 q / v \quad\left(v=\right.$ kinematic water viscosity, $\left.\mathrm{m}^{2} / \mathrm{s}\right) \quad$ (Abrahams et al. 1992) and combining Eqs. (6), (8), and (5), one has 


$$
q=u h=h \sqrt{\frac{8 g h S_{0}}{f}}=\frac{\left(8 g S_{0}\right)^{1 / 2} h^{3 / 2}}{\sqrt{k\left[3.19\left(\frac{4 q}{v}\right)^{-0.45}+b\right]}}
$$

where $q=$ unit discharge of overland flow. Eqs. (6), (7), and (9) constitute the kinematic wave overland flow model.

\section{Soil Infiltration Model}

A revised Green-Ampt model (Mein and Larson 1973) was used to determine the soil infiltration. The governing equations for this model can be written as

$$
\begin{gathered}
i=\frac{d I}{d t}=K\left[1+\left(\theta_{S}-\theta_{i}\right) S / I\right] \\
I=K t+S\left(\theta_{s}-\theta_{i}\right) \ln \left[1+\frac{I}{S\left(\theta_{s}-\theta_{i}\right)}\right]
\end{gathered}
$$

where $I=$ cumulative infiltration quantity $(\mathrm{m}) ; i=$ infiltration rate $(\mathrm{m} / \mathrm{s}) ; K=$ saturated hydraulic conductivity of soil (or infiltration coefficient) $(\mathrm{m} / \mathrm{s}) ; \theta_{s}=$ saturated volumetric water content, i.e., the effective porosity $\left(\mathrm{cm}^{3} / \mathrm{cm}^{3}\right) ; \theta_{i}=$ initial volumetric water content $\left(\mathrm{cm}^{3} / \mathrm{cm}^{3}\right)$; and $S=$ soil suction $(\mathrm{m})$.

When rainfall intensity $p$ is greater than the infiltration capacity, the water begins to pond on the ground. When the infiltration rate $i$ equals $p$, ponding occurs, and the cumulative infiltration $I_{p}$ from the Green-Ampt model is

$$
I_{p}=\frac{\left(\theta_{s}-\theta_{i}\right) S}{p / K-1}
$$

from which the ponding time

$$
t_{p}=I_{p} / p
$$

is obtained. Thus, the infiltration rate in the whole overland flow process can be expressed as

$$
\begin{gathered}
i=p \quad t \leqslant t_{p} \\
i=K\left[1+\left(\theta_{s}-\theta_{i}\right) S / I\right] \quad t>t_{p}
\end{gathered}
$$

where $I=$ cumulative infiltration after the ponding time (including $I_{p}$ ). Since ponding does not occur at $t=0$, Eq. (14) is revised as

$$
K\left[t-\left(t_{p}-t_{s}\right)\right]=I-S\left(\theta_{s}-\theta_{i}\right) \ln \left[1+\frac{I}{S\left(\theta_{s}-\theta_{i}\right)}\right]
$$

in which $t_{s}<t_{p}$ represents the time needed for reaching the same accumulated infiltration $I_{p}$ (or $i=p$ ), supposing ponding occurs initially, which is determined as

$$
K t_{s}=I_{p}-S\left(\theta_{s}-\theta_{i}\right) \ln \left[1+\frac{I_{p}}{S\left(\theta_{s}-\theta_{i}\right)}\right]
$$

The main idea of revision is to assume that the ponding infiltration occurs from the very beginning. Therefore, the infiltration curve, since ponding starts, should be translated to the left by $t_{p}$ $-t_{s}$. By translating this curve back to the right by $t_{p}-t_{s}$, one gets the actual value of infiltration.

\section{Model of Runoff Generation}

Runoff generation consists of infiltration and surface flow. Therefore, the governing equations for surface runoff and infiltration on hillslopes can be written as
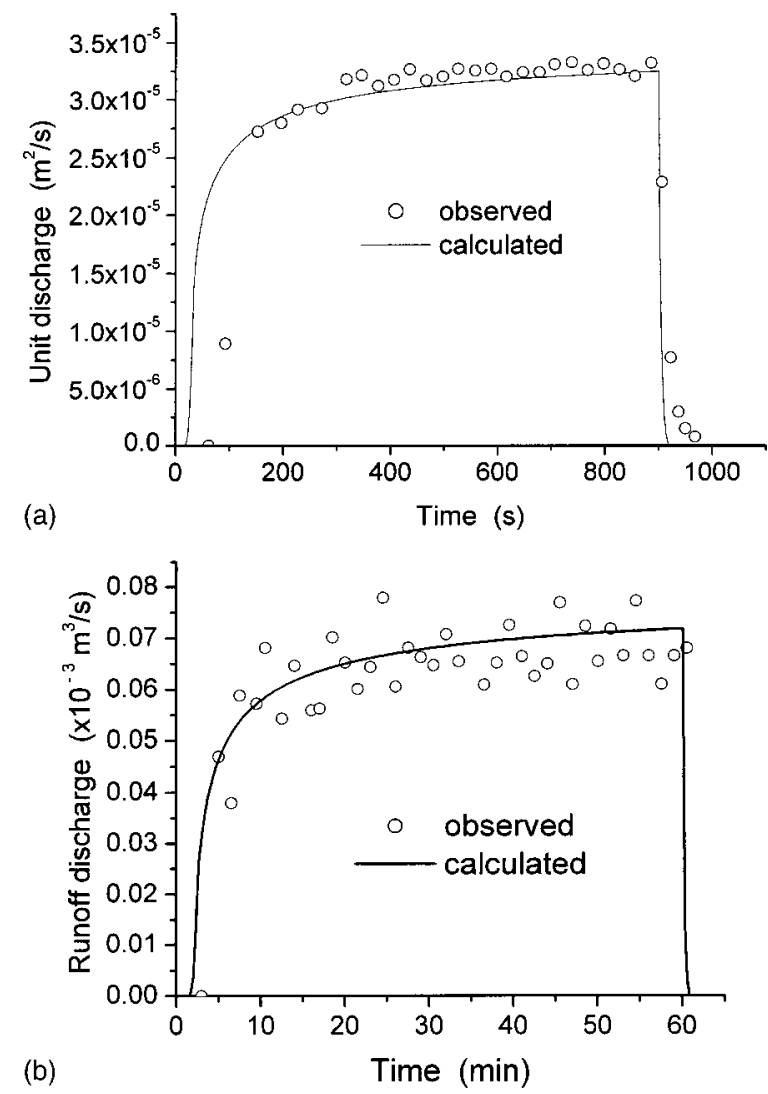

Fig. 1. Simulated and experimental results of the runoff generation diagram on a permeable slope

$$
\begin{gathered}
\frac{\partial h}{\partial t}+\frac{\partial q}{\partial x}=p \cos \theta-i \\
q=\frac{\left(8 g S_{0}\right)^{1 / 2} h^{3 / 2}}{\sqrt{k\left(3.19\left(\frac{4 q}{v}\right)^{-0.45}+b\right)}} \\
i= \begin{cases}p & t \leqslant t_{p} \\
K\left[1+\left(\theta_{s}-\theta_{i}\right) S / I\right] & t>t_{p}\end{cases}
\end{gathered}
$$

In Eq. (19), I may be calculated by Eq. (15) where $t_{p}$ and $t_{s}$ are calculated by Eqs. (13) and (16), respectively. Eq. (17) can be solved numerically using the following finite-difference scheme:

$$
\frac{h_{j}^{n+1}-h_{j}^{n}}{\Delta t}+\frac{q_{j}^{n}-q_{j-1}^{n}}{\Delta x}=\left(S_{r}\right)_{j}^{n}
$$

in which $S_{r}=p \cos \theta-i$. Letting $h=h_{j}$ in Eq. (18), $q_{j}$ can be calculated by iteration.

\section{Model Validation}

Two sets of data were employed to verify the model: (1) the experimental data of Lima (1992), and (2) our experimental data from China. Lima (1992) conducted experiments on a $1.0 \times 0.5 \mathrm{~m}$ flume with a slope $S_{0}=0.1$. The rainfall intensity was 0.03741 $\mathrm{mm} / \mathrm{s}$, and the soil parameters were $K=1.67 \times 10^{-6} \mathrm{~m} / \mathrm{s}, \theta_{s}$ $=0.506, \theta_{i}=0.0107, S=0.02 \mathrm{~m}$. Fig. 1(a) shows a comparison of calculated and experimental unit discharges at the outlet. In 
general, the surface of the slope always has, to some extent, ponding capability. The neglect of the surface ponding capability in this model makes the calculated runoff occur earlier than the real runoff in the experiment. Except for the very short initial period, a good agreement between computed and observed discharge values was found, indicating that the kinematic wave model satisfactorily simulated runoff generation on the hillslope.

The other data set was obtained from experiments conducted on a soil flume with artificial rainfall at the Northwestern Institute of Water and Soil Conservation, Chinese Academy of Science, China. The test plot was $320 \mathrm{~cm}$ long, $100 \mathrm{~cm}$ wide, and $30 \mathrm{~cm}$ deep with a slope of $10^{\circ}$. The rainfall intensity was $1.6 \mathrm{~mm} / \mathrm{min}$ and the soil was the local loess of Yangling in the Shanxi province with parameters $K=1.67 \times 10^{-6} \mathrm{~m} / \mathrm{s}, \theta_{s}=0.5027, \theta_{i}=0.2262, S$ $=0.15 \mathrm{~m}$. Fig. $1(\mathrm{~b})$ compares the observed and the predicted runoff discharges at the outlet. Overall, a good agreement was found between observed and predicted discharge hydrographs. The results indicate that the kinematic wave model is capable of adequately simulating the process of runoff generation on the Loess Plateau of Northwest China.

\section{Influence of Slope Surface Conditions on Runoff Generation}

Microtopography and vegetative cover lead to the form resistance and wave resistance, respectively. Thus, for simplicity it is assumed that the influence of surface irregularities on infiltration and water ponding is negligible and their influence on overland flow can be reflected through resistance. The morphological factors that affect overland flow on a hillslope mainly include the gradient and length of the slope, microtopography, and vegetative cover. The morphology of actual hillslopes is indeed extremely complex. For example, the Loess Plateau area of China is wellknown for its unique landform and severe soil erosion, with countless valleys and gullies that result in fragmented geomorphologic characteristics. Due to severe erosion, the areas are demarcated by sheer cliffs, becoming what is known by Chinese geologists as "yuan," "liang," "mao," etc. The length of the slopes varies from a few meters to hundreds of meters, and the slope gradient ranges widely from 0 to $60^{\circ}$. The surface of the hillslopes exhibits local irregularities undulating in the transverse direction, especially grooves. The vegetative cover exhibits a significant variability between cultivated land and uncultivated lands. These extreme differences in surface features and topography lead to different characteristics of runoff generation on the Loess plateau. The influence of these factors on overland flow was analyzed by applying the kinematic wave model to the Loess Plateau of Northwest China. The soil characteristics of this plateau were assumed to be relatively homogeneous and, according to Jiang (1997), they were found to be the following: the saturated moisture content of soil $\theta_{s}=57 \%$; the initial moisture content $\theta_{i}=21 \%$; the soil suction $S=0.06(\mathrm{~m})$; and the infiltration coefficient of soil $K(1-\sin \theta) / 6$, where $K=0.75(\mathrm{~m} / \mathrm{s})$.

\section{Influence of Slope Length and Gradient}

Under the condition of uniform rainfall intensity on a plane slope [taking $k=1$ and $b=0$ in Eq. (19)], runoff generation was simulated for four slope lengths of 6, 20, 40, and $60 \mathrm{~m}$. Fig. 2 shows the calculated unit discharge of runoff $q$ as a function of time for various slope lengths. The modeling showed that the unit discharge increased remarkably as the slope length increased. The

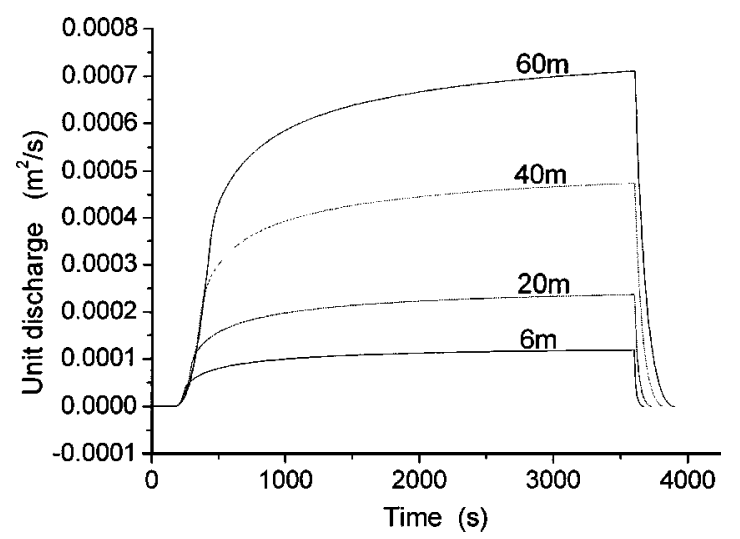

Fig. 2. Unit discharge of runoff as a function of time for various slope lengths

longer the slope was, the larger the unit discharge was. However, the runoff generation time increased only slightly with increasing slope length. On the other hand, the slope length had hardly any effect on the initial time of runoff occurrence.

For a uniform rainfall intensity and a constant slope length, runoff was calculated for 14 slope gradients of $1^{\circ}, 5^{\circ}, 10^{\circ}, 15^{\circ}$, $20^{\circ}, 25^{\circ}, 30^{\circ}, 35^{\circ}, 40^{\circ}, 45^{\circ}, 50^{\circ}, 55^{\circ}, 60^{\circ}$, and $65^{\circ}$. The simulation results were illustrated in Fig. 3. The influence of the slope gradient on overland flow was rather complex. The greater the slope gradient was, the earlier the runoff occurred. On the other hand, the runoff cessation was delayed slightly with increasing slope gradient. For steady runoff, the unit discharge of runoff generally increases as the slope gradient decreases because of the increasing area of rainfall. However, when the slope gradient decreases to some small value, the unit discharge decreases because of the increase in infiltration. The results of this simulation suggest that the unit discharge reaches the minimum value at about $10^{\circ}$ of the slope gradient, and that the water depth decreases with increasing slope gradient.

The effect of slope gradient on the flow velocity and shear stress of overland flow can be both positive and negative [Fig. $3(\mathrm{c})]$. The flow velocity and shear stress $\left(\tau=\gamma h S_{f}\right)$ initially increase and then begins to decrease when the slope gradient reaches a critical value. Although the corresponding critical slopes are not equal, both of them are found within the range of about $40^{\circ}-50^{\circ}$. This range was also found by Liu et al. (2001) in their theoretical analysis.

\section{Influence of Microtopography}

The influence of microtopography was accounted for through parameter $b$ in Eq. (18) ( $b$ represents the irregular extent of slope surface landscape which reflects the form resistance formed by microtopography; the larger $b$ represents more obvious topography. For a uniform rainfall intensity $(p=1 \mathrm{~mm} / \mathrm{min}$, i.e., 1.67 $\left.\times 10^{-5} \mathrm{~m} / \mathrm{s}\right)$ and a fixed percentage of vegetative cover $(k$ $=4.699$ ), runoff generation was simulated for different values of $b$ (the numbers 4,8 , and 9 in Table 1). Fig. 4 shows the simulated unit discharge $q$, velocity $u$, water depth $h$, and shear stress $\tau$ as functions of time. The simulated results show that microtopography has little effect on the unit discharge but largely influences other hydraulic characteristics. With increasing $b$, the velocity at the outlet decreases, while the water depth and the shear stress increase. The rougher the slope surface is, the larger the resistance to overland flow is. This concludes that velocity decreases but the 

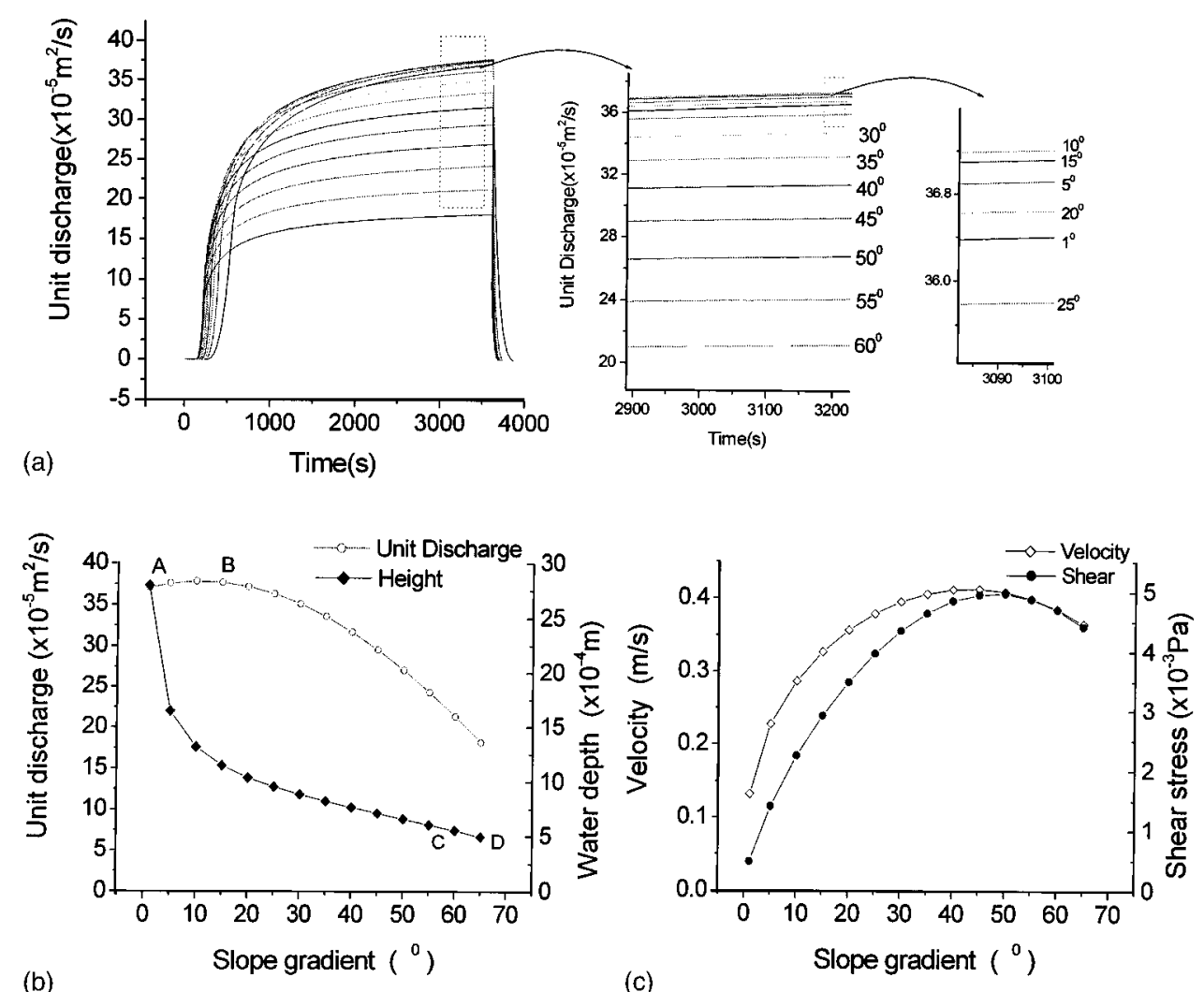

Fig. 3. Runoff generation process and main hydraulic parameters (unit discharge, water depth, velocity, and shear stress) of overland flow for various slope gradients

eroding capability of overland flow (ECOF) increases, i.e., the ECOF increases as the magnitude of microtopography increases. Compared with smooth slopes, the irregular slope surface is more susceptible to erosion by overland flow under the same rainfall intensity. Furthermore, if microtopography leads to the occurrence of rills on hillslopes, soil erosion will be more serious. The simulated results in Fig. 4 show that velocity, water depth, and shear stress of overland flow do not change linearly with $b$. In general, the increasing $b$ value exercises only a small influence on hydraulic characteristics. This indicates that the influence of surface form becomes gradually weaker when the magnitude of topography and gravel-covered increases to a certain extent.

\section{Influence of Vegetative Cover}

The influence of vegetative cover was accounted for through $k$ in Eq. (6). For different values of $k\left(k=e^{2.80 C}, C\right.$ is the percentage of vegetative cover, $\%$ ) shown in Table 1 , runoff generation was simulated for the same rainfall intensity and keeping the topogra-

Table 1. Values of $k$ and $b$ in Different Simulation Cases

\begin{tabular}{crcc}
\hline No. & C $(\%)$ & $k$ & $b$ \\
\hline 1 & 2.0 & 1.140 & 0.0 \\
2 & 10.5 & 1.968 & 0.0 \\
3 & 17.5 & 3.090 & 0.0 \\
4 & 24.0 & 4.699 & 0.0 \\
5 & 2.0 & 1.140 & 2.4 \\
6 & 10.4 & 1.958 & 2.4 \\
7 & 17.5 & 3.090 & 2.4 \\
8 & 24.0 & 4.699 & 2.4 \\
9 & 24.0 & 4.699 & 1.2 \\
10 & 17.5 & 3.090 & 1.2 \\
\hline
\end{tabular}

phy of the hillslope unchanged (i.e., $b$ is constant). Two cases were considered: (1) form resistance is small or $b$ is rather small where the hillslope surface is rather flat; and (2) form resistance is greater or $b$ is larger where there exists obvious topographic irregularities on the hillslope surface. The unit discharge $q$, velocity, water depth, and shear stress were calculated for the two cases for different $k$ values, as shown in Figs. 5 and 6 . These results show that the degree to which the vegetative cover influences overland flow is closely related to the value of $b$, i.e., the magnitude of microtopography.

Fig. 5 shows that when the effect of vegetative cover on interception and soil infiltration is neglected, vegetation cover has little effect on the overland flow discharge and only lengthens the runoff time a little bit. However, the vegetative cover markedly affects other hydraulic characteristics of overland flow. In general, as the vegetative cover increases, the resistance to overland flow increases, which leads to decreased flow velocity but increased water depth and shear stress. This result also shows that with the effect of vegetative cover on the surface ponding capability of slopes and soil infiltration, the total quantity of runoff changes with the variation of vegetative cover and there is also little effect on the runoff discharge process. The vegetative cover mainly influences the hydraulic characteristic by changing the resistance to overland flow.

Fig. 6 shows the results of calculation for different surface slopes with upland and gravel protuberances. The discharge hydrographs for four slopes are almost coincident. The graphs, $v-t$, $h-t$, and $\tau-t$, for the four cases are similar to those shown in Fig. 5. This indicates that the influence of vegetative cover on the unit discharge is weak. With increasing percentage of the vegetative cover, the velocity at the outlet decreases while the water depth and flow shear stress increase. Comparing Figs. 5 and 6, it is seen 

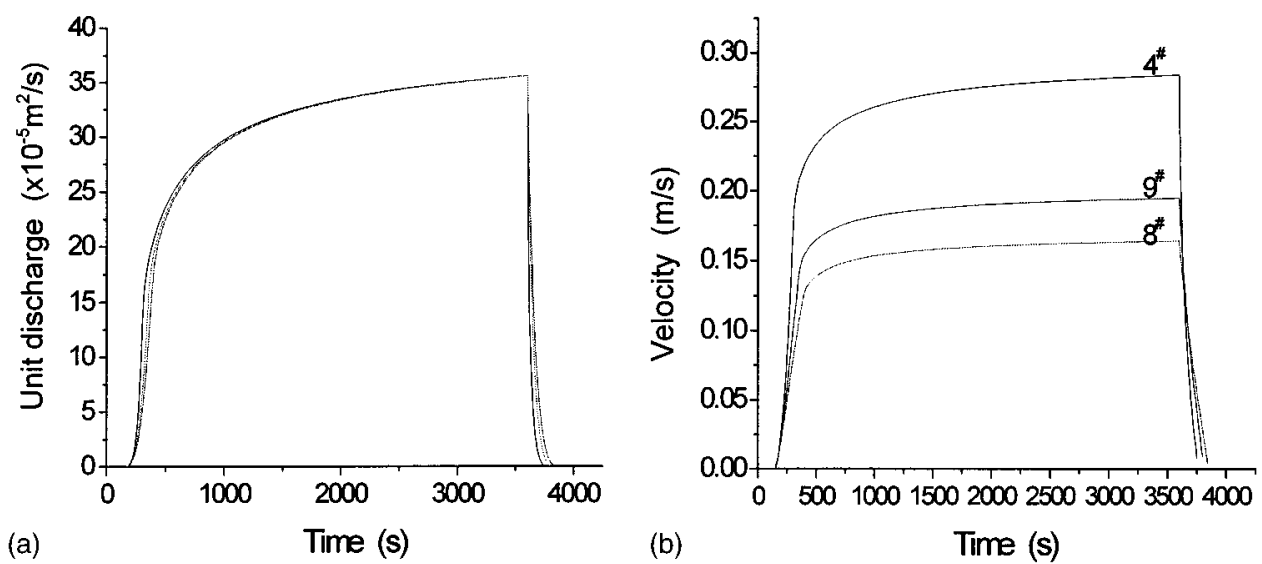

(a)

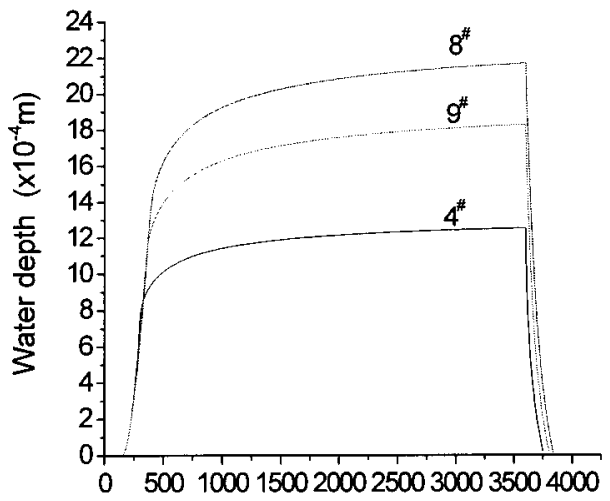

(c)

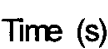

(b)

Time (s)

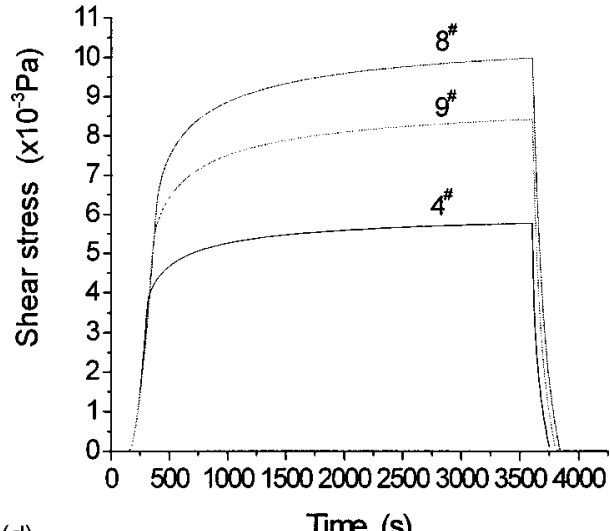

(d)

Fig. 4. Influence of microtopography on overland flow ( $k$ keeps constant)
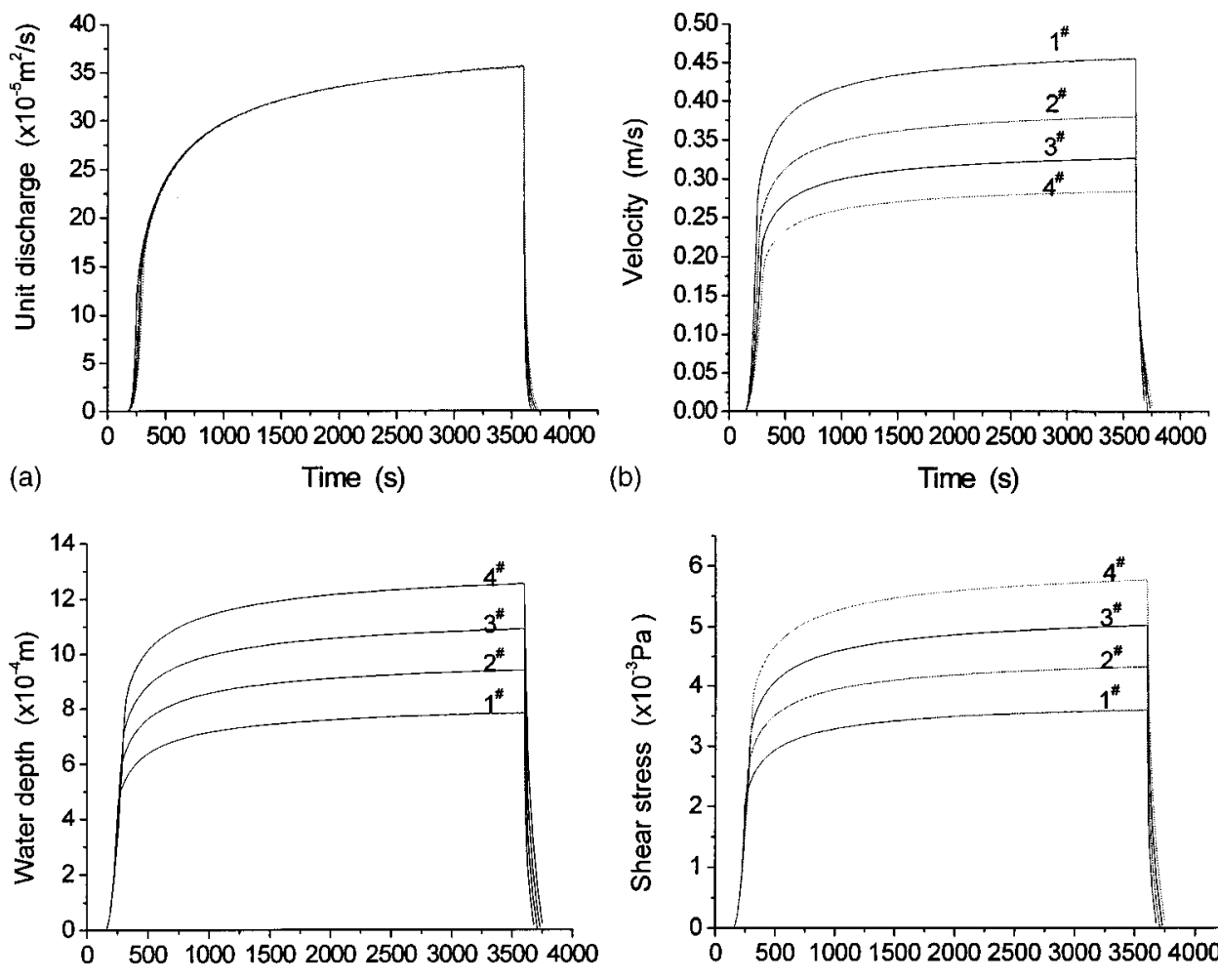

(c)

Time (s)

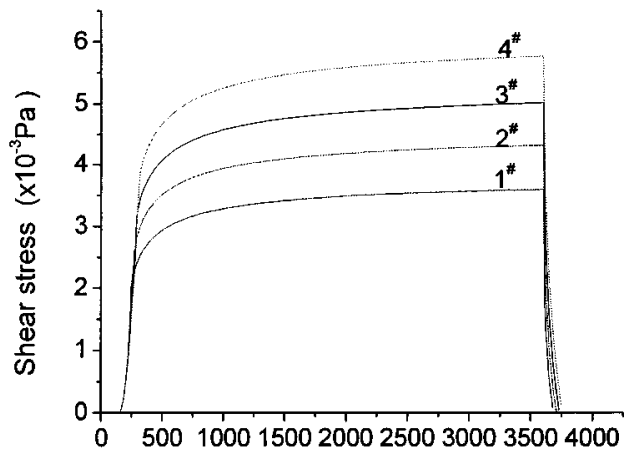

(d)

Time (s)

Fig. 5. Influences of vegetation coverage on overland flow (the form resistance is small, or the hillslope surface is relatively smooth; here $b=0$ ) 

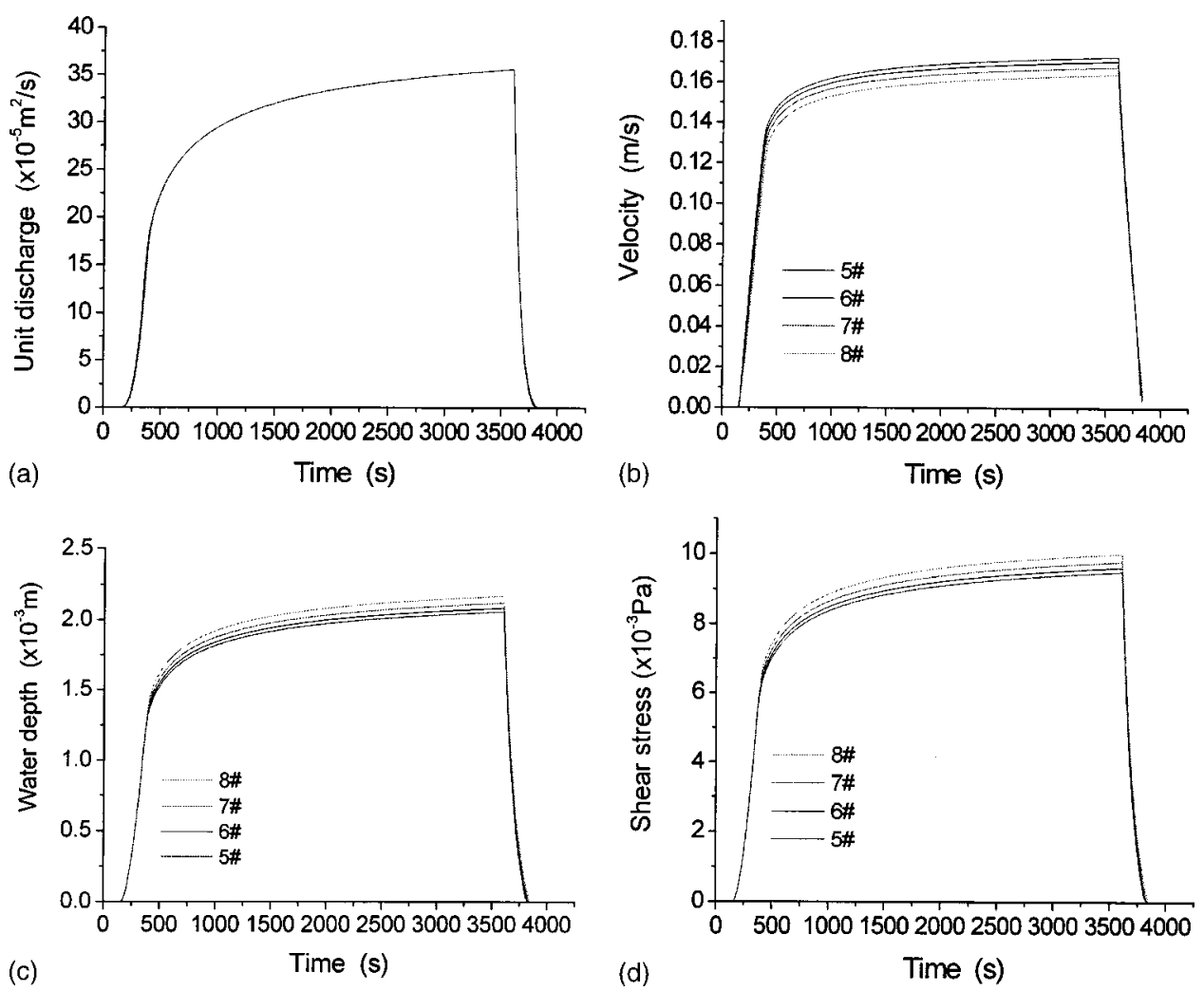

Fig. 6. Influences of vegetation coverage on overland flow (the form resistance is larger, or the hillslope surface exists obvious microtopography; here $b=2.4)$

that the four lines shown in Fig. 6 are very close to each other, indicating that when $b$ is relatively large, i.e., there exists obvious topography and gravel cover, the effect of vegetative cover on various hydraulic characteristics is weak as compared with them on plane bed hillslopes. In this situation (where form resistance is dominating), even if there are dense vegetation, breaking surface wave, and flow separation, the influence on the flow velocity, water depth, and shear stress is relatively weak. In contrast, this influence for plane hillslopes is significant. These results also indicate that the influence of vegetative cover on overland flow is sensitive when the slope surface is relatively flat (form resistance is small) but insensitive when there exists obvious topography and gravel cover on the slope surface (the form resistance is dominating). This suggests that the vegetative cover affecting overland flow on regular surface hillslopes is more egregious.

The above results show that vegetative cover increases the flow resistance that leads to lower flow velocity, but does not decrease the eroding capability of overland flow. This suggests that vegetation-based soil-protective measures mainly strengthen the soil and increase its erosion-resisting capacity, but do not decrease the ECOF. An important practical application of this finding is in design of vegetation-based protective measures for soil conservation.

\section{Conclusions}

The following conclusions are drawn from this study:

1. The effect of microtopography and vegetation cover on overland flow can be treated through grain resistance, form resistance, and wave resistance.
2. The length and gradient of slope manifestly affect runoff generation and other hydraulic characteristics of overland flow. The ECOF increases with increasing slope length. With increasing slope gradient, the flow velocity and shear stress first increase to a peak value, then decrease again, suggesting that there exists a critical slope gradient for flow velocity and shear stress.

3. The microtopography has little effect on the unit discharge of overland flow at outlet, but does affect other hydraulic characteristics of overland flow, such as flow velocity, depth, and shear stress. Irregular hillslopes more easily erode than do regular slopes.

4. The vegetative cover only slightly affects the unit discharge, but the influence on other hydraulic characteristics is more pronounced. With increasing percentage of vegetative cover, the velocity of overland flow decreases, but the water depth and flow shear stress increase. These influences are nonlinear, and they gradually weaken when the magnitude of topography increases. In addition, the protective measures of vegetation mainly enhance the erosion-resisting capacity of soil, but do not decrease the eroding power of overland flow.

\section{Acknowledgment}

This research was financially supported by the Key Project of the Chinese Natural Science Foundation (No. 19832060 and No. 10332050) and by the Innovation Project Foundation of Chinese Academy of Sciences (No. KJCX2-SW-L1).

\section{Notation}

The following symbols are used in this paper: $A_{b}=$ area of slope bed $\left(\mathrm{m}^{2}\right)$; 
$A_{i}=$ wetted cross-sectional area of $i$ th element $\left(\mathrm{m}^{2}\right)$;

$b=$ parameter $\left(=4.8 \Sigma A_{i} / A_{b}\right.$, represents form resistance);

$C=$ concentration of roughness elements (or ratio of vegetation coverage) $(\%)$;

$f=$ Darcy-Weisbach roughness coefficient;

$f_{f}=$ form resistance component;

$f_{g}=$ grain resistance component;

$f_{r}=$ rain resistance component;

$f_{w}=$ wave resistance component;

$g=$ acceleration due to gravity $\left(\mathrm{m} / \mathrm{s}^{2}\right) ;$

$h=$ water depth $(\mathrm{m})$;

$I=$ cumulative infiltration quantity $(\mathrm{m})$;

$I_{p}=$ cumulative infiltration quantity when infiltration rate equal to rainfall intensity $(\mathrm{m})$;

$i=$ infiltration rate of soil $(\mathrm{m} / \mathrm{s})$;

$K=$ saturate conductivity of soil (or infiltration coefficient) $(\mathrm{m} / \mathrm{s})$;

$k=$ parameter $\left(=e^{2.80 C}\right.$, represents the wave resistance);

$p=$ rainfall intensity $(\mathrm{m} / \mathrm{s})$;

$q=$ unit discharge of overland flow $\left(\mathrm{m}^{2} / \mathrm{s}\right) ;$

$q_{*}=$ rain excess $(=p \cos \theta-i)(\mathrm{m} / \mathrm{s})$;

$\mathrm{R}=$ Reynolds number;

$R=$ hydraulic radius $(\mathrm{m})$;

$S=$ soil suction $(\mathrm{m})$

$S_{f}=$ friction slope of flow;

$S_{0}=$ slope gradient $S_{0}=\sin \theta$;

$t=$ time (s);

$t_{p}=$ ponding time $(\mathrm{s})$

$t_{s}=$ time needed for $i=p$ supposing ponding occurs initially (s);

$u=$ mean velocity of overland flow $(\mathrm{m} / \mathrm{s})$;

$x=$ coordinate along slope $(\mathrm{m})$;

$\delta=$ thickness of viscous sublayer;

$v=$ kinematic fluid viscosity $\left(\mathrm{m}^{2} / \mathrm{s}\right)$;

$\theta=$ slope angle $\left(^{\circ}\right) ;$

$\theta_{i}=$ initial volumetric water content $\left(\mathrm{m}^{3} / \mathrm{m}^{3}\right)$;

$\theta_{s}=$ saturate volumetric water content $\left(\mathrm{m}^{3} / \mathrm{m}^{3}\right)$.

\section{References}

Abrahams, A. D., Parsons, A. J., and Hirsch, P. J. (1992). "Field and laboratory studies of resistance to interrill overland flow on semi-arid hillslopes, southern Arizona." Overland flow, A. J. Parsons and A. D. Abrahams, eds., UCL Press, University College London, London, $1-23$.

Angermann, T., et al. (2002). "Runoff from orchard floors-micro-plot field experiments and modeling." J. Hydrol., 265, 178-194.

Casanave, A., and Valentin, C. (1992). "A runoff capability classification system based on surface features criteria in semi-arid areas of West Africa." J. Hydrol., 130, 231-248.

Chen, L., and Liu, Q. Q. (2001). "On the equations of overland flow and one-dimensional equations for open channel flow with lateral inflow." Mech. Eng., 23(4), 21-24 (in Chinese).

Chen, L., Liu, Q. Q., and Li, J. C. (2001). "Runoff generation characteristics in typical erosion regions on the Loess Plateau." Int. J. Sediment Res., 16(4), 473-485.

Chow, V. T. (1959). Open-channel hydraulics, McGraw-Hill, New York.

Dunne, T., and Dietrich, W. E. (1980). "Experimental study of Horton overland flow on tropical hillslopes." J. Hydrol., 88, 343-365.

Einstein, H. A., and Banks, R. B. (1950). "Fluid resistance of composite roughness." EOS Trans. Am. Geophys. Union, 31, 603-610.

Govindaraju, R. S., Kavvas, M. L., and Tayfur, G. (1992). “A simplified model for two dimensional overland flows." Adv. Water Resour., 15, 133-141.
Hirsch, P. J. (1992). "Hydraulic resistance to overland flow on semiarid hillslopes: A physical simulation." PhD dissertation, Dept. of Geography, State Univ. of New York at Buffalo, Buffalo, N.Y.

Jiang, D. S. (1997). "Soil and water loss in Loess Plateau and the regulation mode." Hydraulic and Water Power Press of China, Beijing (in Chinese).

Kirkby, M. J., ed. (1978). Hillslope hydrology, Wiley-Interscience, New York.

Lawrence, D. S. L. (2000). "Hydraulic resistance in overland flow during partial and marginal surface inundation: Experimental observations and modeling." Water Resour. Res., 36(8), 2381-2393.

Li, J. C., Liu, Q. Q., and Zhou, J. F. (2003). "Environmental mechanics in China." Adv. Appl. Mech., 39, 224-312.

Lima, J. L. M. P. (1989). "Overland flow under rainfall: Some aspects related to modelling and conditioning factors." $\mathrm{PhD}$ thesis, Agricultural Univ. Wageningen, Wageningen, The Netherlands.

Lima, J. L. M. P. (1992). "Model KINNIF for overland flow on pervious surface." Overland flow, A. J. Parsons and A. D. Abrahams, eds., UCL Press, University College London, London, 69-88.

Liu, Q. Q., Chen, L., and Li, J. C. (2001). "Influences of slop gradient on soil erosion." Appl. Math. Mech., 22(5), 510-519.

Mein, R. G., and Larson, C. L. (1973). "Modeling infiltration during a steady rain." Water Resour. Res., 9(2), 384-394.

Parsons, A. J., and Abrahams, A. D., eds. (1992). Overland flowhydraulics and erosion mechanics, UCL Press, University College London, London.

Posthumus, H., and Spaan, W. P. (2001). "Rainfall runoff relations for vegetation barriers in the Sahel." Soil Erosion Research for the 21st Century, American Society of Agricultural Engineers, St. Joseph, Mich., 50-53.

Putty, M. R. Y., and Prasad, R. (2000). "Runoff processes in headwater catchment-an experimental study in western ghats, South India." $J$. Hydrol., 235, 63-71.

Saghafian, B., Julien, P. Y., and Rajaie, H. (2002). "Runoff hydrograph simulation based on time variable isochrone technique." J. Hydrol., 261, 193-203.

Shen, B., ed. (1996). "Finite element simulation on surface hydrology." Xi' an Press of Xibei Technology Univ. Xibei, China.

Shen, H. W., and Li, R. M. (1973). "Rainfall effect on sheet flow over smooth surface." J. Hydraul. Div., Am. Soc. Civ. Eng., 99(5), 771792.

Scoging, H. (1992). "Modelling overland-flow hydrology for dynamic hydraulics." Overland flow, A. J. Parsons and A. D. Abrahams, eds., UCL Press, University College London, London, 89-103.

Singh, V. P., eds. (1996). Kinematic wave modeling in water resources: Surface water hydrology, Wiley, New York.

Singh, V. P., and Woolhiser, D. A. (2002). "Mathematical modeling of watershed hydrology." J. Hydrologic Eng., 7(4), 270-292.

Tayfur, G., Kavvas, M. L., Govindaraju, R. S., and Storm, D. E. (1993). "Applicability of St. Venant equations for two-dimensional overland flows over rough infiltrating surfaces." J. Hydraul. Eng., 119(1), 5163.

Tayfur, G. (2001). "Modeling two-dimensional erosion process over infiltrating surfaces." J. Hydrologic Eng., 6(3), 259-262.

Tayfur, G., and Kavvas, M. L. (1998). "A really-averaged overland flow equations at hillslope scale." Hydrological Sciences, 43(3), 361-378.

Wang, G. T., Chen, S. L., Boll, J., Stockle, C. O., and McCool, D. K. (2002). "Modeling overland flow based on Saint-Venant equations for a discretized hillslope system." Hydrolog. Process., 16, 2409-2421.

Woolhiser, D. A., and Ligget, J. A. (1967). "Unsteady one-dimensional flow over a plane-The rising hydrograph.” Water Resour. Res., 3(3), 753-771.

Wu, P. T., and Zhou, P. H. (1994). "Influences of run-drop splash on the hydraulic resistance coefficient of thin water flow." Journal of Soil Erosion and Soil and water Conservation, 8(2), 39-42 (in Chinese).

Yao, W. Y. (1996). "Experimental study on the resistance law of overland flow." J. Sediment Res., (1), 74-81 (in Chinese). 